\title{
FRONTAL LOBE: VARIOUS SULCI PRESENT ON SUPEROLATERAL SURFACE- A MORPHOLOGICAL AND MORPHOMETRIC STUDY
}

\author{
Vijay Laxmi ${ }^{1}$, Bhawna Sharma ${ }^{2}$, Sharma Nidhi ${ }^{* 3}$, RK Sharma ${ }^{4}$. \\ 1,2,4 Department of Anatomy, Government Medical College, Amritsar, Punjab, India. \\ ${ }^{* 3}$ Department of Pharmacology, Government Medical College, Amritsar, Punjab, India.
}

\section{ABSTRACT}

Introduction: The sulci of the human brain are specifically the result of an evolutionary infolding process. These are the anatomical structures which border and divide the adjacent gyri. Knowledge of pattern of sulci and their sulcul and intersulcal length is important for diagnosis of neurological, functional and cognitive disorders.

Aim: The aim of the study is to present the significance of morphological and morphometric measurements of sulci of superolateral surface of frontal lobe and their comparison between right and left cerebral hemispheres. Materials and methods: The study comprised of 50 formalin fixed cerebral hemispheres 25 right and 25 left, of human cadaver of unknown sex which were obtained from the Department of Anatomy, Government Medical College, Amritsar. . All the parameters were taken by using standard digital vernier calliper and calibrated scale. Result and conclusion: All the sulci of superolateral surface of frontal lobe were found to be present in all the specimens of right and left cerebral hemispheres except AHR which was absent in $4 \%(2)$ specimens of the right side. The mean length of CS and PreCS was found to be more in right hemispheres where as mean depth of both sulci was more in left hemispheres. Mean length and depth of lateral sulcus was more in left side as compared to right. Mean length of SFS and IFS was greater in right hemispheres whereas the mean depth of both the sulci was found to be similar in both sides. Hence the differences in sulcul length and depth indicate that the two cerebral hemispheres differ structurally and it can be speculated that some morphological asymmetries could be related to other functional hemispheric specialization.

KEY WORDS: Cerebral cortex, Pattern of sulci, Intersulcal length, Functional hemispheric specialization.

Address for Correspondence: Dr. Sharma Nidhi, Department of Pharmacology, Government Medical College, Amritsar, Punjab, India. E-mail: sharmabhnu11@gmail.com

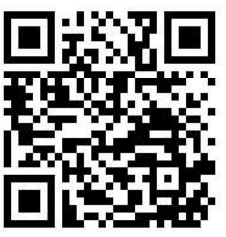

DOI: 10.16965/ijar.2019.193

\begin{tabular}{|l}
$\begin{array}{c}\text { International Jour } \\
\text { ICo.30 } 2016\end{array}$ \\
$\begin{array}{l}\text { ISSN (E) 2321 } \\
\text { https:/// }\end{array}$ \\
Dol-Prefix: ht \\
Received: 01 Apr 2019 \\
Revised: None
\end{tabular}

(1)

\section{INTRODUCTION}

The cerebral cortex is highly extensive in man. To accommodate it in the limited space available within the rigid cranial cavity, the surface of cerebral hemisphere becomes folded, producing numerous convolutions separated by fissures. These convolutions and fissures are termed as Gyri and Sulci respectively [1].

In neurosurgery they are known as main micro anatomical borders that serve as a gateway andsurgical passage to reach the ventricles or to the deeper lesions [2]. Falkai P et.al (1992) observed that schizopherenic patients have shorter lateral sulcus compared to normal subjects. The study also showed that the sylvian asymmetry was more in male schizophrenic than in femaleschizophrenic patients $[3,4]$.

The average sulcal depth decreases at a rate of 
about $0.4 \mathrm{~mm} /$ decade [5]. Depth of central sulcus varies with manual skill and handedness. Right handers have a significantly deeper central sulcus on left hemisphere [6]. Kochnov P, Mangin JF et.al (2005) stated that sulcul depth decreased with age [5]. Thus the anatomical asymmetries of sulci and gyri and their morphometric study is not only important during neurosurgery of brain but may help to explain the range of human talents, recovery from acquired disorders of language function, certain childhood disabilities, some dementing illness of middle life and also hold tremendous significance in diagnosis and management of the diseases of cerebral cortex $[7,8]$.

\section{MATERIALS AND METHODS}

The study comprised of 50 formalin fixed cerebral hemispheres 25 right and 25 left, of human cadaver of unknown sex which were obtained from the Department of Anatomy, Government Medical College, Amritsar. Study was conducted after taking approval from the Institutional Ethics Committee, Government Medical College, Amritsar.

\section{The following parameters were considered during study}

The length and depth of the central sulcus, precentral sulcus, superior frontal sulcus and inferior frontal sulcus, on superolatetral surface of frontal lobe were taken. Presence or absence of sulcus, its continuation, intruption and connection of one sulcus with another was observed.

Length of each sulcus was mesured by taking two refrence points.

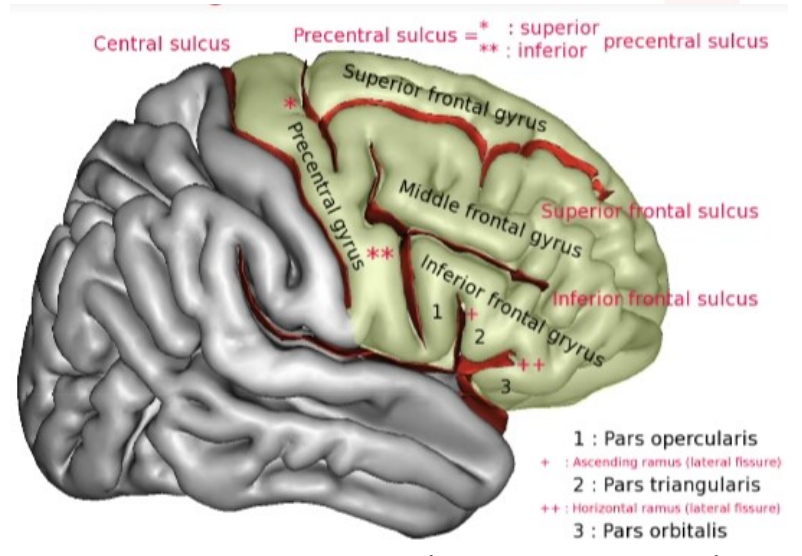

1. Central sulcus: A-(starting point) at superomedial border.

B-(ending point ) at lowermost point of central sulcus where it meets with lateral sulcus and this point is referred as inferior Rolandic point.

2. Precentral sulcus: A-(Starting point) anterior to central sulcus at superomedial border. B- (Ending point) at the posterior ramus of lateral sulcus.

3. Superior frontal sulcus: A- (Starting point) anterior to precentral sulcus. B- (ending point) where it ends near the frontal pole.

4. Inferior frontal sulcus: A- (Starting point) anterior to lower part of the precentral sulcus. B- (Ending point) where it ends near the frontal pole.

\section{Lateral sulcus:}

STEM: A- (starting point) inferior surface of cerebral hemisphere. On reaching the superolateral surface lateral sulcus divided into three ramii. And three ramii diverge from each other at one point and this point is referred as anterior Sylvian point. B- (ending point) - anterior Sylvian point.

Anterior horizontal ramus: A- (starting point) at anterior Sylvian point. B- (ending point) at inferior frontal gyrus.

Anterior ascending ramus: A- (Starting point) at anterior Sylvian point. B- (ending point) posterior to anterior horizontzal ramus on inferior frontal gyrus.

Posterior ramus: A- (Starting point) at anterior Sylvian point. B- (Ending point) at the inferior parietal lobule.

Procedure for measuring sulcal length: The surface of the brain dried with paper towel.The thread was drawn through a needle such that the marked point located inside the eye of the needle. The needle was inserted into the starting point of the sulcus. The office pin was inserted at the ending point of the sulcus. The thread was molded over the course of the sulcus. The thread was marked as it passed over the centre of the head of the office pin.Then, thread was snipped away beyond the marked points and arranged over the measuring scale as straight as possible. The length was measured with reference to the marked points on the thread.

Procedure for measuring the sulcal depth: Sulcal depth was measured by placing the 
vernier calliper vertically inside the sulci

Fig.1 and 2: Showing the procedure for measuring sulcul length.
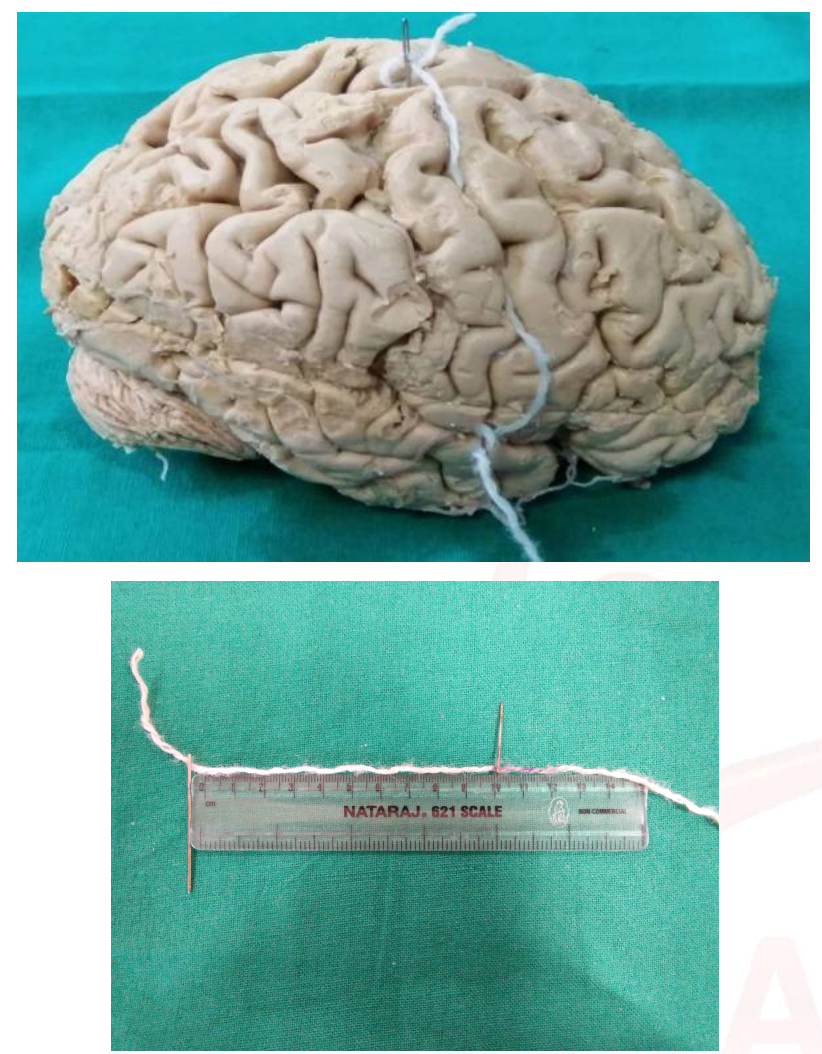

Fig. 3: Showing the measurement of depth.

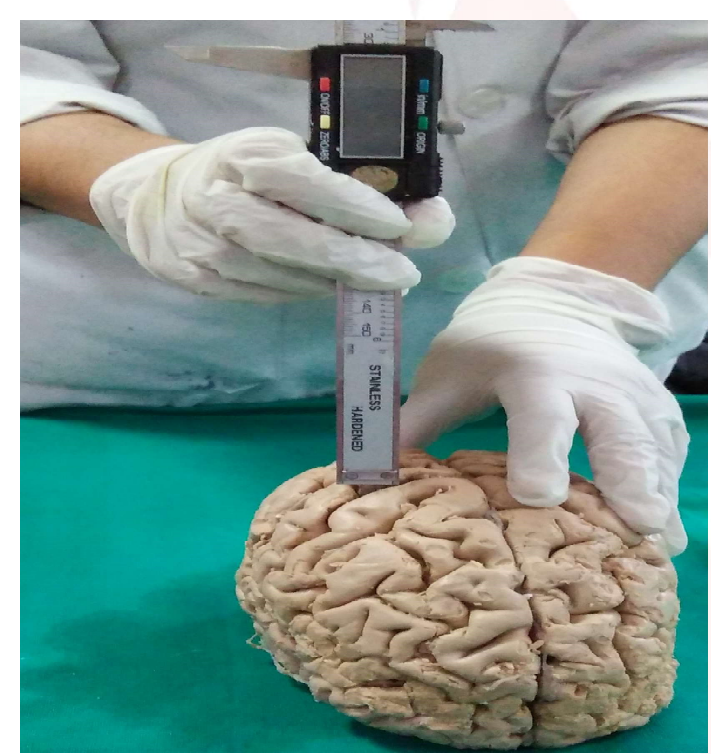

\section{OBSERVATIONS AND RESULTS}

Table 1: Rates for continuous and interrupted structure of sulci.

\begin{tabular}{|c|c|c|c|c|}
\hline \multirow{2}{*}{ SULCI } & \multicolumn{2}{|c|}{$(\%)$ IN RIGHT HEMISPHERE } & \multicolumn{2}{c|}{ (\%)In LEFT HEMISPHERE } \\
\cline { 2 - 5 } & continuous & interrupted & continuous & interrupted \\
\hline CS & $100 \%$ & $0 \%$ & $96 \%$ & $4 \%$ \\
\hline Pre CS & $32 \%$ & $68 \%$ & $36 \%$ & $64 \%$ \\
\hline SFS & $84 \%$ & $16 \%$ & $92 \%$ & $8 \%$ \\
\hline IFS & $80 \%$ & $20 \%$ & $88 \%$ & $12 \%$ \\
\hline
\end{tabular}

Table 2: Showing the connection between sulci.

\begin{tabular}{|c|c|c|c|c|}
\hline $\begin{array}{c}\text { CREBRAL } \\
\text { HEMISPHERES }\end{array}$ & $\begin{array}{c}\% \text { OF } \\
\text { CONNECTION } \\
\text { b/w CS AND } \\
\text { LS }\end{array}$ & $\begin{array}{c}\% \text { OF } \\
\text { CONNECTION } \\
\text { b/w Pre CS and } \\
\text { LS }\end{array}$ & $\begin{array}{c}\% \text { OF } \\
\text { CONNECTION } \\
\text { b/w SFS and } \\
\text { PreCS }\end{array}$ & $\begin{array}{c}\% \text { OF } \\
\text { CONNECTION } \\
\mathrm{b} / \mathrm{w} \text { IFS and } \\
\text { Pre CS }\end{array}$ \\
\hline RIGHT & $48 \%$ & $16 \%$ & $92 \%$ & $88 \%$ \\
\hline LEFT & $60 \%$ & $32 \%$ & $96 \%$ & $92 \%$ \\
\hline
\end{tabular}

Table 3: Showing mean length and depth of sulci in both hemispheres.

\begin{tabular}{|c|c|c|c|c|}
\hline SULCI & \multicolumn{2}{|c|}{ RIGHT } & \multicolumn{2}{c|}{ LEFT } \\
\hline & $\begin{array}{c}\text { length } \\
(\mathrm{M}+\mathrm{SD}) \mathrm{cm}\end{array}$ & $\begin{array}{c}\text { Depth } \\
(\mathrm{M}+\mathrm{SD}) \mathrm{cm}\end{array}$ & $\begin{array}{c}\text { Length } \\
(\mathrm{M}+\mathrm{SD}) \mathrm{cm}\end{array}$ & $\begin{array}{c}\text { Depth } \\
(\mathrm{M}+\mathrm{SD}) \mathrm{cm}\end{array}$ \\
\hline CS & $9.8 \pm 0.4$ & $2.0 \pm 0.4$ & $9.7 \pm 0.8$ & $2.1 \pm 0.4$ \\
\hline Pre CS & $9.2 \pm 1.3$ & $1.7 \pm 0.4$ & $9.1 \pm 1.3$ & $1.9 \pm 0.4$ \\
\hline $\begin{array}{c}\text { LS } \\
\text { (stem + posterior ramus) }\end{array}$ & $10.1 \pm 0.8$ & $2.5 \pm 0.9$ & $10.2 \pm 0.9$ & $2.6 \pm 0.1$ \\
\hline STEM & $3 \pm 0.6$ & $2.4 \pm 0.5$ & $3.2 \pm 0.6$ & $2.8 \pm 0.6$ \\
\hline AHR & $2.3 \pm 0.5$ & $1.5 \pm 0.5$ & $2.5 \pm 0.4$ & $1.5 \pm 0.2$ \\
\hline AAR & $3 \pm 0.6$ & $1.8 \pm 0.5$ & $2.8 \pm 0.6$ & $1.5 \pm 0.4$ \\
\hline PR & $7.1 \pm 0.9$ & $2.3 \pm 0.6$ & $7.2 \pm 0.9$ & $2.4 \pm 0.5$ \\
\hline SFS & $9.7 \pm 1.3$ & $1.8 \pm 0.4$ & $8.6 \pm 1.7$ & $1.8 \pm 0.4$ \\
\hline IFS & $8.8 \pm 1.2$ & $2.1 \pm 1.3$ & $8.6 \pm 1.9$ & $2.1 \pm 1.3$ \\
\hline
\end{tabular}

Table 4: Comparison of connection of CS with LS.

\begin{tabular}{|c|c|c|c|}
\hline AUTHOR & YEAR & $\begin{array}{c}\text { \% IN RIGHT } \\
\text { HEMISPHERE }\end{array}$ & $\begin{array}{c}\% \text { IN LEFT } \\
\text { HEMISPHERE }\end{array}$ \\
\hline Ebling et al [9] & 1989 & $13 \%$ & $4 \%$ \\
\hline Ono et al [2] & 1990 & $16 \%$ & $19 \%$ \\
\hline Ribas et al [10] & 2006 & $17 \%$ & $17 \%$ \\
\hline Yucel et al [11] & 2013 & $28 \%$ & $28 \%$ \\
\hline Present Study & 2018 & $48 \%$ & $60 \%$ \\
\hline
\end{tabular}

Table 5: Comparison of connection of SFS and IFS with PreCS.

\begin{tabular}{|c|c|c|c|c|c|}
\hline \multirow{2}{*}{ AUTHOR } & \multirow{2}{*}{ YEAR } & \multicolumn{2}{c|}{$\begin{array}{c}\text { \% OF CONNECTION } \\
\text { b/w PreCS and SFS }\end{array}$} & \multicolumn{2}{c|}{$\begin{array}{c}\text { \% OF CONNECTION } \\
\text { b/w Pre CS and IFS }\end{array}$} \\
\hline \multirow{2}{*}{ Ono et al [2] } & \multirow{2}{*}{1990} & RIGHT & LEFT & RIGHT & LEFT \\
\cline { 3 - 6 } & & $92 \%$ & $100 \%$ & $68 \%$ & $76 \%$ \\
\hline Jutch et al [12] & 2005 & $74 \%$ & $87 \%$ & $61 \%$ & $78 \%$ \\
\hline Yucel et al [11] & 2013 & $80 \%$ & $80 \%$ & $90 \%$ & $90 \%$ \\
\hline Present study & 2018 & $92 \%$ & $96 \%$ & $88 \%$ & $92 \%$ \\
\hline
\end{tabular}

\section{DISCUSSION}

Presence: The presence of central sulcus, precentral sulcus, superior frontal sulcus, inferior frontal sulcus, posterior ramus of lateral sulcus, anterior ascending ramus of lateral sulcus was $100 \%$ in the study.Whereas the presence of anterior horizontal ramus was found to be(23) $96 \%$ (absence(2) 4\%) in right side and $100 \%$ in left side.

Continuity: From the table 1 it is clear that the central sulcus was continuous in all the 
$25(100 \%)$ specimens of right side. But in the left side it was continuous in 24 (96\%) and interrupted in 1 specimen. Precentral sulcus was continuous in 8 (32\%) and interrupted in 17 (68\%) specimens of the right side and it was continuous in $9(36 \%)$ and interrupted in16 (64\%) specimens of left side. SFS was continuous in 21 (84\%) and interrupted in 4 specimens of the right side and continuous in 23(92\%) and interrupted in 2 specimens of left side. IFS was continuous in 20 $(80 \%)$ and interrupted in 5 specimens of the right side and it was continuous in $22(88 \%)$ and interrupted in $3(12 \%)$ specimens of left side respectively. These differences did not have any statistical significance.

Connection: Connection of central sulcus with the lateral sulcus was found in 12 (48\%) specimens of the right and $15(60 \%)$ of left hemispheres. Percentage of connection of CS with LS was greater in left side as compared to right side. Connection of the precentral sulcus with lateral sulcus was found in $4(16 \%)$ specimens of right side and 8 (32\%) specimens of left side. 23 (92\%) specimens of right and 24 (96\%) specimens of left side showed connection between the SFS and PreCS. 22(88\%) specimen of right and 23 specimens of left side also showed the connection between IFS and PreCS. These observations were in consonance with previous studies done by Ebling et $\mathrm{al}^{9}$, Ono et $\mathrm{al}^{3}$, Ribas et $\mathrm{al}^{10}$, Yucel et $\mathrm{al}^{11}$ as shown in table no.4. Differences that were noted between the right and left sides did not have any statistical importance

Length and depth: From the above table it is clear that. mean length of various sulci of right and left hemispheres were CS (R-9.8,L-9.7), PreCS (R-9.2,L-9.1), LS(R-10.1-L-10.2) AHR (R-2.3, L-2.5), AAR (R-3,L-2.8), SFS (R-9.7, L-8.6) IFS $(8.8, \mathrm{~L}-8.6) \mathrm{cm}$ respectively. Similarly mean depth of CS (R-2,L-2.1),PreCS(R-1.7,L-1.9), LS(R-2.5, $L-2.6) A H R(R-1.5, L-1.5) A A R(R-1.8, L-1.5)$, $\mathrm{SFS}(\mathrm{R}, \mathrm{L}=1.8), \mathrm{IFS}(\mathrm{R}, \mathrm{L}=2.1) \mathrm{cm}$ respectively. The difference in the mean values of length and depth of the sulci indicates that the two cerebral hemispheres are not identical.

\section{CONCLUSION}

Presence of all the sulci were $100 \%$ the study except AHR, which was absent in $4 \%$ specimens of the right side. Connectivity rate of LS with CS and SFS, IFS with PreCS was found to be greater in left side. The CS, PreCS, SFS, IFS was found to be interrupted in some specimens as shown in table no.1. The mean length of CS and PreCS was found to be more in right hemispheres where as mean depth of both sulci was more in left hemispheres which indicate that right handers have a significantly deeper central sulcus on left hemisphere. Mean length and depth of lateral sulcus was more in left side as compared to right. Mean length of SFS and IFS was greater in right hemispheres whereas the mean depth of both the sulci was found to be similar in both sides. Hence it can be concluded that there is usually morphological and morphometric partial asymmetry between the right and left hemispheres of the cerebrum. To correlate this anatomical asymmetry with functional aspects, further studies are required.

\section{ABBREVIATIONS}

CS - Central sulcus

PreCS - Precental sulcus

SFS - Superior frontal sulcus

IFS - Inferior frontal sulcus

LS - lateral sulcus

AHR - Anterior horizontal ramus,

AAR - Anterior ascending ramus,

PR - Posterior ramus,

M - Mean, SD - Standard deviation,

R- Right, L- Left.

\section{Conflicts of Interests: None}

\section{REFERENCES}

[1]. Vishram Singh. Textbook of clinical neuroanatomy. Chapter 12. 2nd edition. Elisevier. A division of Relx. India private limited,141-51.

[2]. Ono M, Kubik S, Abernathy CD, 1990, Atlas of the cerebral sulci. New York: Georg Thieme Verlag 1990;62-74.

[3]. Knaus TA, Tager-Flusberg H, Foundas AL. Sylvian fissure and parietal anatomy in children with autism spectrum disorder. Behav Neurol. 2012;25:32739.

[4]. Kivisaari R, Rapeli P, Van Leemput K, Kähkönen S, Puuskari V, Jokela O, et al. Cerebral measurements and their correlation with the onset age and the duration of opioid abuse. J Opioid Manag, 2010;6:423-s.

[5]. Kochunov P, Mangin JF, Thomas C, Lancaster J, Thompson P, Riviere D, et al. Age-related morphology trends of cortical sulci. Human Brain Mapping 2005;210-20. 
[6]. Zilles K, Schleicher A, Langemann C, Amunts K, Monosun P, Gallagher NP, et al. Quantitative analysis of sulci in the human cerebral cortex: development, regional heterogeneity, gender difference, asymmetry, intersubject variability and cortical architecture. Human Brain Mapping 1997;218-21.

[7]. Galaburda AM, LeMay M, Kemper TL, Geschwind N. Right- left asymmetrics in the brain.Science., 1978;199(4331):852-6 and 06-13.

[8]. Pankaj Kumar Singh, Rakesh Gupta, 2015,Morphometry of the Central Sulcus in the Brain of Uttar Pradesh Region. International Journal of Scientific Study. 2015;3(5):1-4.

[9]. Ebeling U, Steinmetz H, Huang Y, Kahn T. Topography and identification of the inferior precentral sulcus in MRI imaging. Am J neuroradiol, 1989;10:937-42.
[10]. Ribas gc, Ribas ec, Rodrigues c. the anterior sylvian point and the suprasylvian operculum. neurosurg Focus 2005;18(6b):e2.

[11]. Yucel Gonul. Ahmet Songur. Ibrahim Uzun. Ramazan Uygur. Ozan Alper Alkoc. Veli Caglar. Hudaverdi Kucuker. Morphometry, asymmetry and variations of cerebral sulci on superolateral surface of cerebrum in autopsy cases, Springer-Verlag France Surgical and RadiologicAnatomy 2014;36(7). DOI: 10.1007/s00276-013-1237-7.

[12]. Juch H, Zimine I, Seghier MI, lazeyras F, Fasel HD. Ana- tomical variability of the lateral frontal lobe surface: implication for intersubject variability in language neuroimaging. Neuroimage. 2005;24:50414.

How to cite this article:

Vijay Laxmi, Bhawna Sharma, Sharma Nidhi, RK Sharma. FRONTAL LOBE: VARIOUS SULCI PRESENT ON SUPEROLATERAL SURFACEA MORPHOLOGICAL AND MORPHOMETRIC STUDY. Int J Anat Res 2019;7(3.1):6701-6705. DOI: 10.16965/ijar.2019.193 